\title{
Imagen metalingüística: una propuesta para la escrita de correspondencias en la clase de redacción técnica en español
}

Rita Rodrigues Souza ${ }^{1}$

\begin{abstract}
Resumen
En este artículo, se expone una propuesta didáctica de uso de imágenes para la escritura de correspondencias en sala de clase de español, específicamente, en la asignatura de Redacción Técnica en el Curso Técnico en Secretariado en la modalidad de Educación de Jóvenes y Adultos. Busca resaltar el valor de los estudios de género textual, del análisis de necesidades y del uso de imágenes en el contexto formal de educación. Así, discute la importancia de esos recursos visuales como herramienta didáctica en las clases de español como lengua extranjera en la escrita de correspondencias personales en la enseñanza técnica.
\end{abstract}

Palabras clave: Imagen Metalingüística. Géneros textuales. Educación de Jóvenes y Adultos.

\section{Resumo}

Neste artigo, expõe-se uma proposta didática de uso de imagens para a escrita de correspondências em sala de aula de espanhol, especificamente, na disciplina de Redação Técnica no Curso Técnico em Secretariado na modalidade de Educação de Jovens e Adultos. Busca ressaltar a importância dos estudos de gênero textual, da análise de necessidades e do uso de imagens no contexto formal de educação. Assim, discute a importância desses recursos visuais como ferramenta didática nas aulas de espanhol como língua estrangeira com ênfase na produção escrita de cartas pessoais no ensino técnico.

Palavras-chave: Imagem Metalinguística. Análises de Necessidades. Educação de Jovens e Adultos.

El lenguaje es una música con muy variadas melodías. [...] se refiere a las variaciones que se producen por decisiones estilísticas del autor, guiadas, casi siempre, por una aspiración a expresarse lo mejor posible y a sintonizar con los interlocutores y con el contexto. (REYES, 1999, p. 47)

\section{Introducción}

El uso de imágenes, en sala de clase, ya es una práctica consolidada. Estudiosos como Busto y Bedoya $(2009$, p. 2) resaltan que la relevancia del uso de la imagen en el proceso de enseñanza y aprendizaje de una lengua extranjera (LE) se relaciona "con la capacidad humana para crear imágenes mentales por medio de visualizaciones que atraigan nuestra atención, que nos estimulen, o nos provoquen emoción." Sostienen también que la imagen, para ese público en específico, puede promocionar una mayor implicación y una mejor asimilación de la lengua objeto.

\footnotetext{
${ }^{1}$ Doutora em Estudos Linguísticos pela Universidade Estadual Paulista (Unesp). Professora do Instituto Federal de Goiás (IFG), Câmpus Jataí. Atua no Ensino Médio Técnico Integrado Integral e pesquisa sobre tecnologias aplicadas à educação no grupo NINE (http://www.nine.inf.br).
}

LínguaTec, Instituto Federal de Educação, Ciência e Tecnologia do Rio Grande do Sul, Bento Gonçalves v. 3, n. 1, p. 45-70, jun. 2019. 
En este artículo, el énfasis del uso de la imagen se da en el ámbito de la producción del texto con el uso de la imagen metacognitiva (IM). Según Simón (2016), la IM, en sala de clase de lenguas, posibilita comunicar conceptos a los estudiantes de una manera directa con el uso de la propia lengua para explicarla, con apoyo de recursos como colores, subrayado, flechas y otros medios para hacer hincapié en una determinada información.

En el relato de experiencia, sobre el Taller Manejo Didáctico de la Imagen, Vicente (2009) comentó que el dicho taller fue diseñado teniendo como foco la relación entre un recurso específico- la imagen - con los objetivos de una asignatura. Es en ese sentido que proponemos el uso de imagen en el aula de escrita de redacción técnica en español. La autora afirma que queda, pues, "una especie de vacío conceptual por la falta de análisis de las estrategias didácticas y sus actividades como puente conector de los objetivos con los recursos" (VICENTE, 2009, p. 13). Con este estudio, buscamos rellenar parte de ese vacío.

Organizamos la escritura de este artículo presentando, inicialmente, una fundamentación teórica acerca del género textual, seguido de una síntesis sobre imágenes y análisis de necesidades. En la segunda sección del artículo, presentamos la problematización, o sea, lo que ha generado la necesidad del estudio. En la tercera, sugerimos una propuesta de uso de IM.

\section{Fundamentación Teórica}

En esta sección, presentamos un recogido primeramente sobre las concepciones de género textual que fundamentan la propuesta didáctica para el trabajo con cartas personales. En segundo lugar, tratamos sobre la carta personal. En tercer, presentamos los tipos y funciones de imágenes, con énfasis en el IM. Por último, discutimos sobre el análisis de necesidades.

\subsection{Concepciones de género textual}

La concepción de género que fundamenta la propuesta didáctica de trabajo con una IM se apoya en los estudios de Swales (1990), Dean (2008) y Devitt $(1993,2004)$. Antes de proceder a la presentación y discusión del concepto de género de esos autores, es necesario 
abrir un paréntesis para tratar sobre la importancia de elegir una Teoría de Género² para el desarrollo de la actividad pedagógica en sala de clase.

Creemos, como Dean (2008), que silos estudiantes piensan que existe solamente un camino cierto para escribir, el conocimiento de una teoría de género puede ayudarlos a comprender la necesidad de adaptar la escritura a situaciones ya problemas de su entorno social. Ese conocimiento también ayuda los estudiantes a entender qué puede resultar si ellos eligen no adaptarse a las restricciones de un género. Incluso, los estudiantes pueden explotar las potencialidades de elección que los géneros ofrecen. Concordamos también, con Dean (2008), que a partir del momento en que los estudiantes sepan que géneros textuales son más que formas y representan modos de ser y actuar en el mundo, serán aprendices más capaces de realizar elecciones lingüísticas, discursivas y de estructuras textuales más apropiadas a los contextos de uso. Esas escojas, de cierto modo, contribuyen para la estabilidad o para la innovación de los géneros. Así, para escribir, hay varios caminos.

En consonancia con Hyland (2004), un número de ventajas es frecuentemente incluido para el uso de la instrucción de escritura basada en una teoría de género. Las principales ventajas son que la instrucción puede ser explícita, sistemática, basada en necesidades, situada, capacitadora, crítica y concienciadora.

La instrucción basada en género busca ofrecer una comprensión explícita de como los textos están estructurados y porque ellos son escritos de la manera que son, comenta Hyland (2004). El autor enfatiza, aún, que el aprendizaje de la escrita involucra la adquisición de habilidad para el pertinente ejercicio de elección lingüística en la construcción del texto y los profesores pueden apoyarse en eso para proveer los estudiantes con ejemplares de textos con el lenguaje que ellos efectivamente necesitan elaborar.

Retomando las concepciones de género que fundamentan nuestro trabajo con IM, para la escritura de cartas, presentamos Swales (1990) que define género como:

\footnotetext{
2Para una definición de Teoría de Género, adoptamos Dean (2008, p. 3): Teoría de Género es "confusa" y "compleja", para usar las palabras de Amy Devitt, y eso hace que sea difícil de definirla, pero, para mí, ella proporciona respuestas que me ayudan a mejorar la instrucción y la escritura de los alumnos. Esas respuestas hacen valer la confusion y la complejidad. Traducción nuestra de: Genre theory is "messy" and "complex", to use Amy Devitt's words, and that makes it hard to define - but, for me, it provides answers that help me improve my instruction and student writing. Those answers make it worth the mess and complexity.
} 
una clase de eventos comunicativos, cuyos ejemplares comparten los mismos propósitos comunicativos. Esos propósitos son reconocidos por los miembros más expertos de la comunidad discursiva original y constituyen la razón del género. La razón subyacente da el contorno de la estructura esquemática del discurso e influencia y restringe las escojas de contenido y estilo. (SWALES, 1990, p.58, Traducción nuestra) ${ }^{3}$

El género, en Swales (1990), es estudiado bajo una perspectiva sociorretórica, que lo considera como una acción social. El autor tiene en cuenta la naturaleza social del discurso, en que la realización del habla o de la escritura es propuesta para que se llegue a un "propósito" conforme "una situación social", al contrario de analizar el texto en sí mismo, considerándolo como siendo solamente un elemento lingüístico.

El segundo concepto de género, que fundamenta la propuesta, se refiere al presentado por Dean (2008, p. 9. Traducción nuestra.)4: "géneros representan todos los tipos de interacción (algunos textuales y algunos no), son definidos más por la situación que por la forma, son dinámicos y flexibles, y son más una explicación sobre la interacción social que un sistema de clasificación." La definición de género propuesta por Dean (2008) evidencia el amplio alcance de situaciones sociales que el género representa $y$, así, pasan a tener determinadas identidades (género "a", género " $b$ ", género $\infty^{5}$ ) más por las restricciones lingüístico-discursivas, retóricas y propósitos comunicativos impuestas por las situaciones retóricas que por la forma en sí.

De acuerdo con Dean (2008), en la teoría retórica de género se enfatizan los siguientes puntos de estudios: (1) los textos diarios, del trabajo o escolares; (2) la situación y el contexto se relacionan con las regularidades textuales; (3) la dinamicidad, fluidez de la naturaleza de género; (4) la mezcla de límites entre los géneros; y, (5) el modo de desarrollar géneros a partir de otros géneros.

El tercer y último concepto, que fundamenta la propuesta de IM, se apoya en Devitt $(1993,2004)$. Devitt $(1993)$, por ejemplo, comenta que género es una respuesta dinámica a una

\footnotetext{
${ }^{3} \mathrm{~A}$ genre comprises a class of communicative events, the members of which share some set of communicative purposes. These purposes are recognized by the expert members of the parent discourse community, and thereby constitute the rationale for the genre. This rationale shapes the schematic structure of the discourse and influences and constrains choice of content and style.

${ }^{4}[. .$.$] genres represent all sorts of interactions (some textual and some not), are defined more by situation than$ form, are both dynamic and flexible, and are more an explanation of social interaction than a classification system.

${ }^{5}$ Símbolo de Infinito. Es muy usado en las matemáticas y en la física.
} 
situación recurrente, que cambia históricamente y en diferentes grupos sociales, que se adapta y modifica a la medida que el contexto social cambia. Esa concepción de género es considerada nueva por la autora, porque a partir de esa concepción se posibilitó la superación de diversas dicotomías.

Una de las dicotomías superadas, de acuerdo con Devitt (1993), es la representada por la oposición productos y procesos. Siendo que el primer se refieren a los textos (oral o escrito), que son la materialización de los géneros de texto. El segundo, por su vez, tratan sobre el conjunto de acciones que se realizan en la producción de un texto. Según Devitt (1993), es posible integrar productos y procesos y aclara el valor de los productos o textos estudiados. La autora afirma que el producto puede contribuir para la comprensión del proceso y de la recepción del discurso. Esa teoría de género revela y explica la centralidad del género para la escritura, su importancia para la comprensión de como los escritores y la escritura funcionan. Al final, la capacidad del género para capturar forma y situación, tanto restricción como escoja, puede capturar la esencia de la escritura también. De ese modo, Devitt (2004, p. 219. Traducción nuestra.) ${ }^{6}$ afirma que

\footnotetext{
géneros permean vidas. Las personas los usan, consciente e inconscientemente, de forma creativa y formulaica, para las funciones sociales y propósitos individuales, con consciencia crítica e inmersión ciega, en el pasado y aún hoy. Ellos moldan nuestras experiencias, y nuestras experiencias los moldan. Al estudiar y enseñar esas formas de actuar simbólicamente con los demás, podemos aproximarnos de una comprensión no solamente de géneros, sino también de maneras confusas y complejas que los seres humanos se relacionan en sus mundos.
}

La naturaleza ideológica y el poder de géneros se hicieron obvios para estudiosos de género, Devitt (2009) reafirma. La autora asevera, releyendo Carolyn Miller (1984, 1994), que los géneros son entendidos hoy como acciones en contextos sociales y se incorporan a las cuestiones de valores y creencias de los grupos de poder. Resalta, también, que el género emerge, se desarrolla y cambia. Eso trae implicaciones para el proceso de enseñanza y

\footnotetext{
${ }^{6}$ Genres pervade lives. People use them, consciously and unconsciously, creatively and formulaically, for social functions and individual purposes, with critical awareness and blind immersion, in the past and yet today. They shape our experiences, and our experiences shape them. As we study and teach these ways of acting symbolically with others, we may, be approaching an understanding not just of genres but of the messy, complex ways that human beings get along in their worlds.
} 
aprendizaje de género que pueden ser aclaradoras y libertadoras, si los géneros son enseñados como parte de una consciencia crítica más amplia. De modo que, para explotar pedagógicamente un determinado género, es necesario abordar el contexto de ese género en que sean contemplados la cultura, la situación y otros géneros.

El género afectará de cualquier manera el aprendizaje de los alumnos se les enseñamos géneros explícitamente o no, aboga Devitt (2009). Defiende, aún, que nosotros, profesores, también necesitamos reconocer que el conocimiento de géneros específicos es necesario en la academia, en las asignaturas y en el ejercicio de las profesiones. Añade que, si enseñamos un determinado género de modo explícito, inevitablemente vamos enseñarlos de forma incompleta, perolos alumnos van a entender más sobre él de lo que entenderían si no les tuviéramos enseñado nada sobre ese género, afirma Devitt (2009). Así que, la autora propone un trabajo de concienciación crítica de género con los estudiantes. Teniendo en cuenta todo lo dicho, debemos considerar que:

\begin{abstract}
La variedad de géneros es enorme y las fronteras bastante cambiantes, pero reconocemos intuitivamente los diferentes tipos de texto en cada acto de producción e interpretación verbal, y debemos adquirir el entrenamiento necesario para escribir textos que cumplan con los requisitos de su género, si no queremos arriesgarnos a que nuestro mensaje sea difícil de interpretar, o incluso incomprensible. Los géneros no son corsés, sino moldes (garantizadores de funcionalidad) que encuadran y potencian la creatividad de quien escribe. (REYES, 1999, p.38,énfasis nuestro.)
\end{abstract}

El énfasis final en la cita refuerza la importancia del uso de IM para la enseñanza de producción de texto en sala de clase. La IM puede funcionar como un tipo de "molde funcional" para fomentar la escritura creativa del estudiante, principalmente los de niveles más básicos y estudiantes de la Educación de Jóvenes y Adultos

En síntesis, las definiciones de género de Swales (1990), Dean (2008) y Devitt (1993; 2004) nos enseñan como el trabajo de escrita, en sala de clase, puede ser potenciado si consideramos las características de los géneros de texto y cómo ellas se materializan en los textos. El uso pedagógico de esas características sumadas a otros aspectos importantes de la escrita, como ortografía, acentuación, coherencia, cohesión, por ejemplo, podría contribuir para el desarrollo del alumnado. 
Por fin, en este artículo, género de texto se puede entender como una herramienta de comunicación e interacción, que presentan características que pueden ser adaptadas a la situación y propósito comunicativo, por el usuario de la lengua.

2.2 La carta: lenguaje, estructura y contexto de uso

Hoy día, la escritura de carta es un tema a ser resignificado en sala de clase. Con los cambios sociales, ese género de texto, de un modo general, ha pasado por transformaciones en su uso. Aclaramos que ese tema es importante en este artículo, pues en el contexto de actuación del secretario y de la secretaria, en una empresa, de una manera general, la escrita de correspondencias está presente.

Partimos de las definiciones de carta de Reyes (1999). Para esa autora, la carta es un mensaje firmado por alguien y dirigida a alguien. Cualquiera quesea su propósito, puede ser de tres tipos, los cuales sintetizamos en el siguiente cuadro:

\begin{tabular}{|l|l|}
\hline Tipo & Características \\
\hline $\begin{array}{l}\text { Cartas } \\
\text { privadas }\end{array}$ & $\begin{array}{l}\text { Dirigidas a familiares y amigos. } \\
\text { Por ejemplo: contar a un amigo como estamos pasando las vacaciones. }\end{array}$ \\
\hline $\begin{array}{l}\text { Cartas } \\
\text { profesionales }\end{array}$ & $\begin{array}{l}\text { Dirigidas a colegas, colaboradores, pacientes o discípulos. } \\
\text { Por ejemplo: ofrecer un producto a la venta o comentar algún trabajo con un colega. }\end{array}$ \\
\hline $\begin{array}{l}\text { Cartas } \\
\text { comerciales }\end{array}$ & $\begin{array}{l}\text { Dirigidas a clientes y empleados. Las cartas comerciales son de muchos tipos: solicitud } \\
\text { de informes sobre una empresa, solicitud de precios, acuses de recibo, pedidos, } \\
\text { solicitudes de trabajo, convocatorias a entrevistas, ofertas, contratos, currículos. } \\
\text { Por ejemplo: informar a un cliente de que hemos tenido que cerrar su cuenta en el } \\
\text { banco. }\end{array}$ \\
\hline
\end{tabular}

Cuadro 1: Tipos de cartas personales

Fuente: Elaborado por la autora a partir de la lectura de Reyes (999).

Otros tipos de cartas, que también pueden considerarse personales, son las cartas en las que realizamos trámites burocráticos, que por lo general se escriben en formularios que hay que rellenar, o constan solamente de una o dos fórmulas inalterables, estipuladas por las instituciones como parte de sus protocolos, según Reyes (1999).

Las tres categorías de cartas - privadas, profesionales y comerciales - pueden ser electrónicas, que difieren en el canal utilizado y, a veces, también en su función, redacción, estilo y presentación, comenta Reyes (1999). El medio electrónico ha facilitado mucho la circulación de mensajes variados, cuando no se necesita la validación del texto escrito en 
papel y cuando se quiere aprovechar la facilidad y la rapidez de la comunicación. “A veces el correo electrónico, como el teléfono, precede a una comunicación más formal puesta en papel”, confirma Reyes (1999, p. 289)

Los tipos de cartas personales, presentados por Reyes (1999), se distinguen uno del otro por el lenguaje, estructura y contexto de uso. Pero, una sirve de soporte para las otras si consideramos que "como parte de nuestra competencia comunicativa, todos tenemos establecidas asociaciones entre funciones y rasgos discursivos" (REYES, 1999, p. 33). Sin embargo, no podemos olvidar que "los textos escritos deben estar siempre debidamente contextualizados, deben contener, por fuera y por dentro, señales que orienten al lector sobre como leerlos" (REYES, 1999, p. 34). Con el adviento de la internet, el soporte de las correspondencias, en muchas situaciones, pasó a ser electrónico, como cartas de publicidad de productos y servicio.

En ese proceso de contextualización, de enseñar al lector las marcas, nos parece ser propicio el uso de IM. Las señales, sean lingüísticas o no, son pasibles de volverlas en imágenes comprensibles al estudiante $y$, con eso, potenciar el aprendizaje. Así, Reyes refuerza que

\begin{abstract}
al reflexionar para componer un texto, al planear su contenido y sus características discursivas, al insertar nuestro escrito en un género determinado, nuestras elecciones están influidas, o deberían estarlo, por la situación y por el contexto. Contextualizar un texto es usar todas las marcas de identificación necesarias para que se pueda insertarlo en un género, y además calcular la distribución de su información: cuál se da por compartida con el auditorio y puede inferirse y, cuál es nueva. Participan en este proceso autores y lectores: no se olvide que un texto es un diálogo, un lugar de encuentro. (REYES, 1999, p. 34)
\end{abstract}

De acuerdo con Reyes (1999), el planteamiento de un texto debe considerar la situación y el contexto si deseamos tener éxito en la interacción. Para eso, hace falta proponer un "molde" que permita al estudiante demostrar su capacidad creativa, pero dentro de los posibles límites del contexto de producción y recepción de texto. Como marcas visuales del texto se pueden destacar: la disposición visual del texto, el título, espacios, tipos de letra, subrayar una palabra, por ejemplo, es una clave de contextualización por lo cual se informa al lector acerca de las intenciones comunicativas del autor: se le hace notar (sin 
decirlo explícitamente) que ese tema es importante. Según Reyes (1999), todo eso orienta al lector y le permiten inferir significados de un texto. Como la ejemplifica la autora:

\begin{abstract}
En las cartas, los encabezamientos suelen ser el punto de partida de un proceso de inferencias por parte del lector. Cuando escribimos a una colega, por ejemplo, a veces podemos elegir el encabezamiento: si elegimos "estimada amiga" frente a otras opciones como "distinguida colega" o "estimada señora", damos lugar a ciertas inferencias sobre nuestras posiciones en el intercambio, la actitud de quien escribe la carta y la función de la carta. Lo mismo sucede con la elección de cierto vocabulario, de ciertas metáforas, de ciertos giros. (REYES, 1999, p. $34-35$ )
\end{abstract}

La administración de la información (qué digo, cuánto digo, en qué orden digo, a qué le doy más importancia) es uno de los aspectos más importantes de la contextualización (REYES, 1999, p.35). Conscientemente, o no, cada vez que usamos el lenguaje damos huellas de contextualización al nuestro interlocutor, ayudando así a nuestro público a evocar ciertos conocimientos o creencias comunes a ambas partes, y que consideramos necesarias o deseables para el buen éxito de la comunicación. Cuando escribimos, esa selección de claves de contextualización pasa a ser más consciente (REYES, 1999, p.36). Como presenta el epígrafe, en el inicio del artículo, que "el lenguaje es una música con muy variadas melodías" (REYES, 1999, p. 47), las variaciones del lenguaje son una realidad y debemos poner atención en ellas para que nuestra interacción sea más efectiva en las más diversas situaciones y contextos, en especial en las diferentes correspondencias.

El registro, es decir, conjunto de diferencias provocadas por la relación entre el texto y sucontexto situacional, es una de las variaciones más importantes para que los sentidos sean construidos de modo apropiado. Los registros se presentan como "maneras de hablar", coloraciones, tonos de los textos, tonos que se relacionan con elementos de la situación en que se producen los textos (especialmente quiénes hablan, de qué hablan, por qué medio hablan). Como los registros son resultados de selecciones hechas por el hablante o escritor, ellos son aspectos del estilo de un texto (REYES, 1999, p. 47).

Por lo general, se considera que el contexto situacional, en el cual sucede una interacción lingüística, tiene tres rasgos ya indicados: el tema de la comunicación, la relación entre los participantes y el papel del lenguaje en esa interacción. El registro surge de la correlación entre los rasgos lingüísticos y esos tres rasgos del contexto: Campo: de qué se 
trata, qué pasa (tipo de acción social realizada); Tenor: quiénes participan (las relaciones entre los participantes); Modo: que papel desempeña el lenguaje (papel que desempeña el lenguaje en ese acto comunicativo).En las cartas podemos, sintetizar el registro de la siguiente manera:

\begin{tabular}{|c|c|c|}
\hline \multicolumn{3}{|c|}{ REGISTRO } \\
\hline Tenor & Campo & Modo \\
\hline $\begin{array}{l}\text { Las cartas privadas admiten } \\
\text { varios grados de informalidad, } \\
\text { desde el más informal hasta el } \\
\text { formal, dependiendo de la } \\
\text { función de la carta y de su } \\
\text { destinatario. }\end{array}$ & $\begin{array}{l}\text { En las cartas privadas y } \\
\text { profesionales puede utilizar el } \\
\text { vocabulario y los tipos de } \\
\text { construcción requeridas por el } \\
\text { tipo de transacción que está } \\
\text { realizando con la carta, como } \\
\text { en cualquier otro escrito, pero } \\
\text { evitando la acumulación de } \\
\text { voces técnicas o de cultismos, } \\
\text { que darán a su carta un tono } \\
\text { pedante. }\end{array}$ & $\begin{array}{l}\text { En las cartas privadas, en las } \\
\text { que usted usa el lenguaje con } \\
\text { gran libertad, este puede } \\
\text { desempeñar un papel muy } \\
\text { importante: demostrar } \\
\text { camaradería, solidaridad con el } \\
\text { destinatario. }\end{array}$ \\
\hline $\begin{array}{l}\text { Las cartas profesionales } \\
\text { abarcan también varios grados } \\
\text { de formalidad. No deben ser } \\
\text { tan informales como las } \\
\text { privadas, pero pueden ser } \\
\text { informales, dependiendo de la } \\
\text { relación con el destinatario. Por } \\
\text { regla general, son, sin embargo, } \\
\text { formales, y a veces también } \\
\text { contienen fórmulas de cortesía } \\
\text { estipuladas. }\end{array}$ & $\begin{array}{l}\text { En las cartas comerciales debe } \\
\text { usar los sistemas lingüísticos } \\
\text { requeridos por la situación, que } \\
\text { suelen ser específicos. }\end{array}$ & $\begin{array}{l}\text { En las cartas profesionales, el } \\
\text { lenguaje muestra también } \\
\text { solidaridad entre los miembros } \\
\text { de una comunidad discursiva, y } \\
\text { demás revela la competencia } \\
\text { del autor en el manejo de los } \\
\text { recursos lingüísticos adecuados. }\end{array}$ \\
\hline $\begin{array}{l}\text { Las cartas comerciales deben } \\
\text { tener un tenor formal, pero no } \\
\text { exagerado. Recuerde que la } \\
\text { impersonalidad y las frases } \\
\text { hechas hacen las cartas menos } \\
\text { efectivas. Puede usar la } \\
\text { primera persona "institucional". }\end{array}$ & & $\begin{array}{l}\text { En las cartas comerciales, desde } \\
\text { la calidad del papel hasta la } \\
\text { corrección gramatical delatarán } \\
\text { la seriedad de una empresa. } \\
\text { Siga todas las convenciones } \\
\text { lingüísticas (que veremos) y } \\
\text { nunca descuide los detalles. }\end{array}$ \\
\hline
\end{tabular}

Cuadro 2: El registro en las cartas

Fuente: Elaborado por la autora a partir de Reyes (1999).

Hay una correspondencia directa entre los tres rasgos del contexto y ciertos sistemas lingüísticos, ya sea el vocabulario, el modo verbal o los deícticos (palabras que aluden a elementos de la situación: tú, aquí, este, etc.). El sistema de los pronombres personales del español, por ejemplo, prevé dos formas distintas de tratamiento, tú (informal) y usted (formal) manifiesta un aspecto de la correlación entre el tenor del contexto y el texto; esa 
correlación forma parte de su registro. Si usamos tú, el tenor será más informal que si usamos usted.

Por las informaciones del Cuadro 2, podemos verificar que las cartas personales poseen características que las distinguen de otros tipos de correspondencias. Sin embargo, dentro de la propia categorización, los límites son tenues y el usuario del lenguaje necesita poner atención al contexto de producción.

Las características presentadas, del uso del registro en las cartas, son pasibles de presentación esquemática para los estudiantes por medio de imágenes, favoreciendo el aprendizaje por medio de una IM. Una presentación esquemática se refiere a la presentación de las informaciones más importantes de modo objetivo. En la sección siguiente, presentaremos posibilidades de trabajo pedagógico con imágenes.

2.3 Tipología y funciones de las imágenes en sala de clase

Acerca del estado del arte sobre el uso de las imágenes en sala de clase, Simón (2016) lo hace en su artículo La imagen metalingüística como imagen pedagógica en E/LE. A partir del estudio hecho, propone una tipología, la cual sacamos provecho para nuestra propuesta de uso de imágenes en clases de producción de texto.

Primeramente, Simón (2016) aclara que hace falta analizar la función comunicativa (FC) de la imagen, la que se refiere al tipo de información que objetiva transmitir y cómo lo hace. A partir de esa función, propone la siguiente tipología:

1. Figurativas: representan un objeto, ente o concepto con referencia en el mundo real o imaginario.

2. Decorativas: hacen los materiales de aprendizaje visualmente más atractivos. En muchas ocasiones este tipo de elementos visuales son formas abstractas de diseño moderno o emulan entornos informáticos.

3. Asociativas: remiten a un tipo de contenido o procedimiento determinado. En general, se trata de recuadros de distintos colores, sólidos o degradados, delimitados por líneas continuas o discontinuas, en cuyo interior se incluye contenido textual que remite a 
diferentes tipos de contenidos.

4. Complementos visuales: facilitan la comprensión de un texto o una tarea. Pueden ser imágenes figurativas, signos, símbolos o iconos que acompañan un texto o una instrucción con el fin de clarificar la información que éstos contienen.

5. Organizativas: organizan la información de forma que pueda ser aprehendida de forma secuencial o pueda establecerse visualmente una jerarquía entre conceptos.

6. Metalingüísticas: se tratan, resumidamente, de imágenes que comunican y transmiten conceptos sin necesidad de recurrir a la intervención, siempre distorsionadora, de una lengua; ya sea la materna o una lengua extranjera que se esté estudiando. El objetivo es en realidad sencillo: intentar abrir una vía alternativa y complementaria para transmitir y recibir conocimiento que podría ser gran utilidad en entornos de enseñanza.

Acerca de la función asociativa, Simón (2016) asevera quelas variaciones de tipología textual son un mecanismo recurrente y efectivo para focalizar la atención del alumno y establecer una asociación entre un determinado color o variación tipológica con un concepto determinado o procedimiento. Ese autor afirma que los materiales, que él consultó, utilizan la negrita, la cursiva o distintos colores para asociar la palabra resaltada con un vocabulario especialmente importante por su significado o por el papel que juega en la resolución de un determinado ejercicio.

Otra práctica común es el resaltado en negrita y/o en diferentes colores de variaciones morfológicas de determinadas palabras (concordancias de género y número, terminaciones verbales, etc.). Esa función se acerca a lo que proponemos, sin embargo, lo que está en el centro de nuestra propuesta es el metalenguaje que promueva la escritura y detención de conceptos relacionados al lenguaje, estructura y contexto de uso de cartas.

En segundo lugar, propone una explotación de la función didáctica (FD) de los tipos de imágenes en lo relativo a la enseñanza de idiomas, como por ejemplo de Español como Lengua Extranjera (E/LE). Para esto, se apoya en los estudios de Cone (1982) que presentan las funciones introductoria, explicativa, iniciadora y motivadora. La conjugación de las dos clasificaciones posibilita una relación entre funciones comunicativas y didácticas, asegura Simón (2016).

A partir de la percepción de la relación entre la FC y la FD, Simón (2016) ratifica su 
propuesta que la imagen puede ser utilizada como herramienta de reflexión metalingüística y con esa función, la denomina de IM. Es posible que otras también sean empleadas, pero para los objetivos y contenidos que pretendemos tratar, es la que más se adecua.

Meditar sobre las funciones de las imágenes en sala de clase es una actividad muy necesaria en el trabajo docente de planificación de un curso o de una clase. Como afirmamos en el inicio del artículo, ya es una práctica usarlas, pero hay que contextualizarlas siempre de acuerdo con los objetivos y contenidos. Además, la percepción de que en cada momento histórico ellas asumen diferentes funciones. Considerar todo eso puede ayudarnos, a nosotros/as profesores/as, a comprender, porque para:

\begin{abstract}
muchos profesores [...] el trabajo con ellas les resulta deficiente, pues no consiguen satisfacer sus expectativas o las de sus estudiantes; en ocasiones una escasa reflexión sobre la explotación de una actividad, sobre el formato más adecuado o la función de una imagen dentro de un tema, puede generar el fracaso de una sesión completa. A la hora de elegir y de llevar una imagen a la clase ELE es importante que nos plateemos primero, y analicemos después, una serie de factores que faciliten la tarea de conseguir su mejor explotación didáctica. (BUSTO; BEDOYA, 2009, p. 4)
\end{abstract}

Considerando las palabras de Busto y Beyoda (2009), el conocimiento de las funciones de las imágenes, o mejor, las funciones que las imágenes asumen de acuerdo con los propósitos y contextos de uso constituyen una variable a ser considerada por el profesorado. Esas autoras hacen hincapié que se debe considerar, de ese modo, si el tipo de imagen elegida se acerca a los intereses de la clase y si su explotación haya sido fruto de una buena reflexión por parte del profesor. Son factores que ponen en relieve la importancia de la acción de plantear la clase en función de objetivos y contenidos específicos cuando se usa la imagen como uno de los recursos didácticos.

Añaden, también que, a los factores didácticos, hay la necesidad de la observación de los factores sociales, en especial "aquellos que limitan el uso de ciertas imágenes en determinados contextos, bien por una gran distancia cultural entre la cultura local y la cultura meta, por diferencias en los referentes del grupo, o por las preferencias de los estudiantes" (BUSTO; BEDOYA, 2009, p. 4).

Por su vez, Simón (2016) comenta que algunos beneficios de las IM coinciden con los 
de otros tipos de imágenes como, por ejemplo, la accesibilidad a la información por medio de diferentes canales; inmediatez; facilidad de retención y asociación, entre otras. Para Simón (2016, p. 21), "esto no significa, por supuesto, que estas imágenes funcionen de forma autónoma; por el contrario, se prevé que la efectividad de estas aumente con apoyo o explicaciones verbales". El impacto reside en que en el momento de las explicaciones la asimetría entre imagen y texto se anula, y a veces, incluso, puede invertirse, afirma Simón (2016).

En ese apartado, entonces, quedó resaltada la relevancia de contextualizar el uso de la imagen, asociando con los objetivos y contenidos de la clase o curso y necesidades de los/as estudiantes. El uso de la imagen, considerando sus funciones comunicativas y didácticas, posibilita enseñar de modo más visual la estructura de un texto e instruir a los estudiantes qué aspectos él debe contemplar en cada parte que compone dicha estructura de acuerdo con una determinada situación y propósito comunicativo. Considerando, también las necesidades de los estudiantes, tema de la próxima sección.

\subsection{Análisis de necesidades}

La realización del análisis de necesidades de los estudiantes es un principio central también para la enseñanza basada en género, resalta Hyland (2004). Eso involucra el profesor y el estudiante en un análisis colaborativo en el que ocurre el Análisis de la Situación-Alvo (Target Situation Analysis - TSA)y el Análisis de la Situación-Presente (Present Situation Analysis - PSA).Para Hyland (2004), en conformidad con Songhori (2008) y Benesch (1996, 2006), el PSA se refiere a la necesidad de que los profesores descubran tanto sobre los alumnos cuanto sea posible, y las informaciones pueden ser tanto objetivas (edad, competencia, aprendizajes previos, tiempo disponible, institución), como subjetivas (necesidades de autopercepción, facilidades y dificultades). Ya el TSA aborda el análisis de la situación que concierne a los papeles futuros de los aprendices y las habilidades lingüísticas y conocimientos requeridos para una performance competente en el contexto de la escritura, por ejemplo.

El análisis de necesidades necesita asumir un abordaje que combine procedimientos 
cualitativos y cuantitativos, para que sea posible a obtención de informaciones que permitan conocer los alumnos, tener un perfil de ellos y del grupo, así como la obtención de informaciones que evidencien valores, creencias, conocimientos, defiende Cintra (1992). Cintra y Passarelli (2008, p. 60), por su vez, añaden que la construcción de cuestiones que permitan cuantificar conocimientos, competencias y habilidades de los discentes, en el análisis de necesidades, se ocupa de la identificación de esos elementos de modo que, sea posible, a partir de ellos, "establecer las directrices de un programa educativo basado en objetivos predeterminados." ${ }^{7}$ (Traducción nuestra). Por lo tanto, las cuestiones superan cualquier intención meramente estadística.

Ya Hyland (2004) postula que determinar necesidades es realmente un proceso continuo para que y profesor modifique la enseñanza para que los estudiantes se adapten mejor y construyan un aprendizaje más significativo. El autor afirma que así el profesor puede reconocer si los objetivos iniciales fueran exageradamente altos, o si los estudiantes tienen más conocimientos del género-objeto que demuestren en un análisis de necesidades. Enseñar la escritura no es una sencilla transferencia de habilidades o competencias y el aprendiente, al mismo tiempo, puede tener retornos sociales y aprender para una actividad profesional, argumenta Hyland (2004). De ese modo, el autor nos muestra que las necesidades deben ser abordadas más allá de las necesidades previstas por la institución escuela.

Trabajar en la vertiente de enseñanza de lenguas para fines específicos, como explanado por Cintra y Passarelli (2008), exige cambio de comportamiento del profesor y del estudiante. Del primer, se exige asumir que se no conoce todas las necesidades de los alumnos, por lo tanto, no es capaz de planificar los contenidos de un curso para atender las necesidades de los discentes sin antes realizar un diagnóstico previo y poner atención a los posibles cambios durante del proceso de enseñanza-aprendizaje. Del segundo, se exige que sea y esté sensibilizado, sea y esté motivado, sea y esté más consciente, sepa lo que ya sabe, para descubrir lo que no sabe y, sobre todo, para querer saber algo, eventualmente, aún no

7 "traçar as linhas de orientação de um programa de ensino com base em finalidades previamente determinadas." (CINTRA; PASSARELLI, 2008, p. 60) 
muy claro para él, más conectado a la finalidad del curso.

Debido a la mudanza de comportamiento que Cintra (1992) explicita, el análisis de necesidad se configura en estas tres etapas: autoimagen, acción y reflexión. La primera se refiere a la busca de informaciones en que el discente demuestre lo que cree saber sobre la lectura y la escritura, lo que necesita mejorar, evalúen el propio desempeño, por ejemplo. La segunda se refiere a la ejecución de una actividad de lectura y escritura. La tercera se refiere a un trabajo de contraponer la autoimagen con la acción ejecutada, o sea, se busca proporcionar al discente momento para que él reflexione sobre el propio saber.

El análisis de necesidades es un proceso político y subjetivo, declara Benesch (1996). Algunos - profesores y/o designers - miran para la situación y venlo que los alumnos deben hacer para tener un buen desempeño; otros ven donde existen posibilidades de cambio. $Y$ los que abogan por un análisis de necesidades crítica presuponen, conforme Benesch (1996), que en las instituciones hay jerarquías y que aquellos que están en la parte inferior son los que merecen más poder de lo que tienen, $y$, entonces, procuran las áreas donde se puede alcanzar mayor igualdad.

En el sentido de compromiso de los aprendices, en la actividad de análisis de necesidades, como propuesta por Benesch (1996), Cintra y Passarelli (2008) presentan propuesta análoga, pues abogan que, al realizarse el análisis de necesidades, hay que considerar la correlación de lo emocional con lo racional y asumir que eso tiene consecuencias en la selección de los contenidos presentados a los alumnos, bien como en la forma de proponer cuestiones. Además de la correlación emoción y razón, se debe pensar en la aceptabilidad de las acciones requeridas por los sujetos involucrados. De un lado, el/la alumno/a, como ser racional y emocional, necesita percibir lo que hace falta en un dado curso, para, de hecho, comprometerse con su propio proceso de aprendizaje; de otro, el profesor, como gestor de la enseñanza, necesita de asumir como ser emocional y racional, para, comprometidamente, ejercer su papel de gestor diferenciado por la búsqueda de la mediación. Teniendo en cuenta todo eso, presentamos la situación que ha motivado la proposición de la propuesta didáctica de uso de IM. 


\section{Problematización: las necesidades de los estudiantes}

Una de las etapas del proyecto de investigación intitulado "Secuencia didáctica para la lectura y escrita de textos técnicos en español", ejecutado en uno de los campus del Instituto Federal de Goiás, tuvo como público-objeto estudiantes del Curso Técnico en Secretariado en la modalidad de Educación de Jóvenes y Adultos, fue la aplicación de un cuestionario a los/as participantes.

El cuestionario diagnóstico fue aplicado en el día 24 de enero de 2017. Los nueve alumnos matriculados en el 50 período ${ }^{8}$, correspondiente al semestre lectivo de 2016-2, contestaron el cuestionario tras el aclaramiento de qué se trataba y también después de firmar el termo de consentimiento en participar de la pesquisa. El cuestionario presentó estas 4 secciones: identificación, conocimientos previos, necesidades y expectativas.

En este artículo, vamos presentar solamente los datos de la cuestión 4, que es: Compara los dos textos que siguen en relación al lenguaje, a la estructura y al contexto de uso. Tuvo como función evidenciar cuales contenidos los discentes tenían sobre la escrita de cartas por medio del análisis comparativo de los siguientes textos:

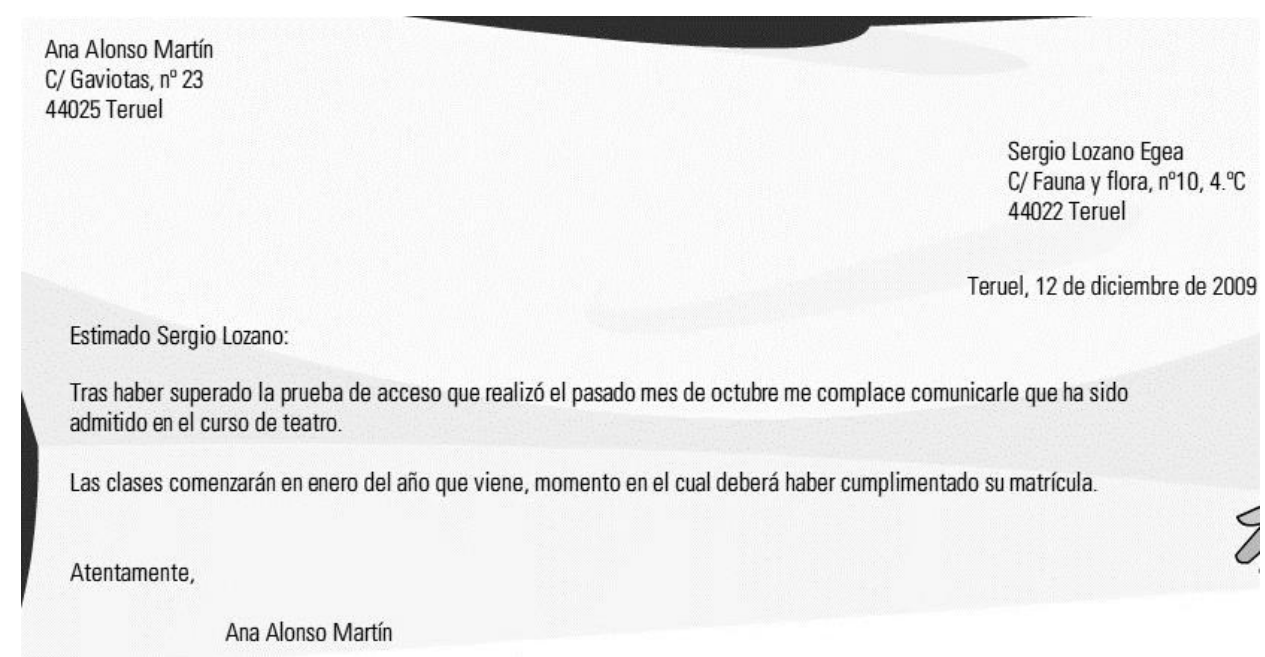

Figura 1: Carta A1

Fuente: Disponible en:

<https://www.edu.xunta.es/espazoAbalar/sites/espazoAbalar/files/datos/1285589414/contido/index.h $\underline{\mathrm{tml}}>$. Accedido en 05 de diciembre de 2016.

\footnotetext{
${ }^{8}$ En el momento de escrita de este artículo, los estudiantes estaban matriculados en el 6o período, pues se ha empezado el año lectivo de 2017-1.
}

LínguaTec, Instituto Federal de Educação, Ciência e Tecnologia do Rio Grande do Sul, Bento Gonçalves v. 3, n. 1, p. 45-70, jun. 2019. 
La carta A1 se refiere a una carta personal del tipo profesional. El remitente objetiva comunicar al destinatario que ese será admitido al curso de teatro tras haber superado la prueba de acceso (campo). Participan de la acción social la persona responsable por hacer el comunicado, y posiblemente, sabe detalles sobre el curso de teatro y, también, participa el interesado en una de las plazas del curso (tenores). El comunicado fue expreso empleando un lenguaje más formal, en que se percibe que entre los interlocutores se establece un alejamiento. Además, la estructura de la carta A1 está bien marcada con características de una correspondencia más formal, por ejemplo, presenta inicialmente, a la izquierda, el nombre completo y la dirección del remitente y abajo, pero, a la derecha, el nombre y la dirección del destinatario. A esas partes, sigue la fecha, ubicada una línea abajo, a la derecha.

El lenguaje de la carta es objetivo. La escoja del vocabulario refleja la preocupación en transmitir, con claridad, informaciones. Se percebe, aún, la preocupación em presentar las informaciones en párrafos distintos. Eso es una característica de objetividad, para evitar que el destinatario se equivoque o no "vea" lo que se quiere informar. El saludo y la despedida enseñan cordialidad y también formalidad (es el modo).

En relación a la carta $\mathrm{B} 1$, se trata de una carta personal del tipo privada.

El remitente objetiva compartir con el destinatario sobre lo que está haciendo debido a la condición de salud en que se encuentra (es el campo). Interactúan en la acción social dos personas que mantienen una relación social de proximidad, pues comparten informaciones (son los tenores). Sigue la carta B1: 


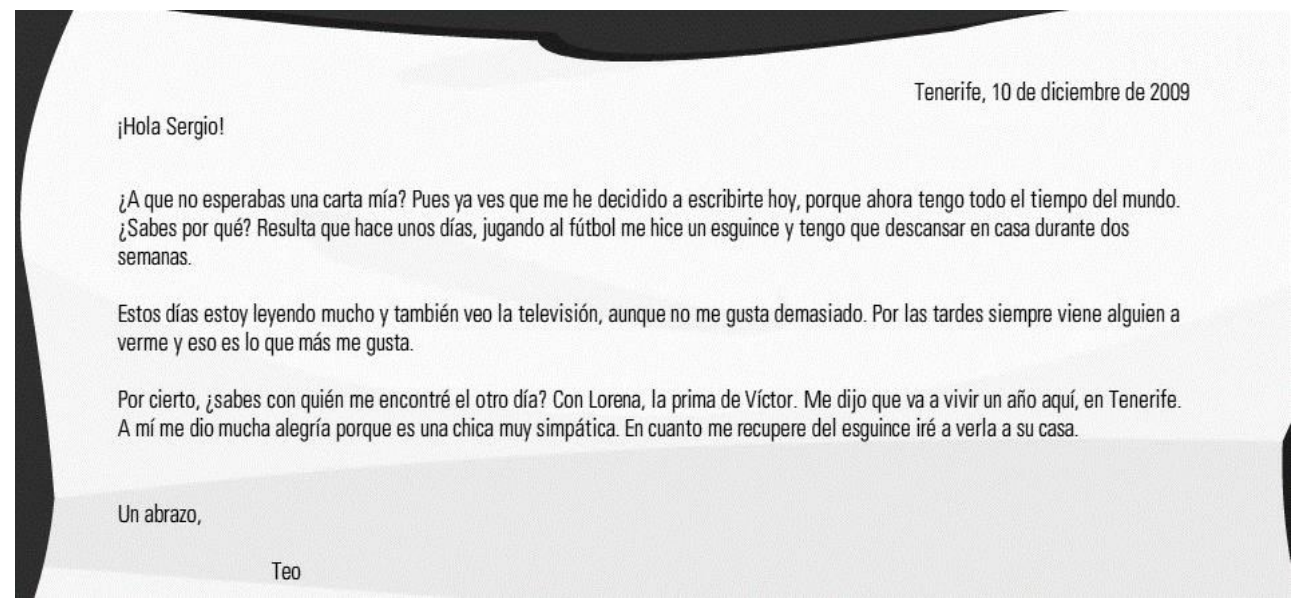

Figura 2 - Carta B1

Fuente: Disponible en:

<https://www.edu.xunta.es/espazoAbalar/sites/espazoAbalar/files/datos/1285589414/contido/index.h

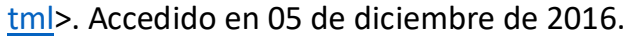

El mensaje, en la carta B1, fue expreso usando un lenguaje más informal, en que se percibe que entre los interlocutores se establece una relación de intimidad. A eso se suma que la estructura de la carta B1 está bien marcada con características de una correspondencia más informal, presentando, primero, la fecha a la derecha, una línea abajo, un saludo usado en contextos comunicativos informales, seguido del nombre del destinatario (es el modo). El lenguaje es más subjetivo. El vocabulario seleccionado demuestra que los interlocutores comparten informaciones. Las informaciones son presentadas en párrafos distintos y con un tono más narrativo. Eso es una característica de subjetividad, para involucrar el destinatario en el tema. El saludo y la despedida enseñan una evidente intimidad entre los interlocutores.

Las respuestas ${ }^{9}$ de los/as participantes llamaron nuestra atención acerca de la necesidad de la proposición de una actividad que pudiera facilitar el aprendizaje. Las respuestas sugieren que los/as estudiantes no presentan dominio de los conceptos solicitados en relación al lenguaje, a la estructura y al contexto de uso. Ese análisis se basa en las respuestas incompletas presentas por todos los discentes. Ellos se centraron entre en el lenguaje, la estructura y el contexto de uso y, en algunos casos, de modo equivocado.

Organizamos las respuestas de ellos de acuerdo con cada aspecto como se presentan

\footnotetext{
${ }^{9}$ Las respuestas de los/as participantes fueron transcriptas con corrección ortográfica una vez que ese tipo de corrección no influencia en el objeto de investigación/propuesta de actividad.
}

LínguaTec, Instituto Federal de Educação, Ciência e Tecnologia do Rio Grande do Sul, Bento Gonçalves v. 3, n. 1, p. 45-70, jun. 2019. 
en el siguiente Cuadro 3:

\begin{tabular}{|c|c|c|}
\hline Lenguaje & Estructura & Contexto de uso \\
\hline $\begin{array}{l}\text { - Texto A - Un lenguaje formal - usa } \\
\text { en cartas más social; texto B - Un } \\
\text { lenguaje informal -usa en el día a } \\
\text { día. (Rose) } \\
\text { - El primer texto es más utilizado en } \\
\text { la escuela de negocios formal. El } \\
\text { segundo es más informal, texto } \\
\text { utilizado en un mensaje o correo } \\
\text { electrónico a amigos. (Sara) } \\
\text { - El primer texto es más formal y fue } \\
\text { utilizado para un comunicado que a } \\
\text { persona había sido aprobado en un } \\
\text { curso de teatro y tendría que hacer } \\
\text { su matrícula. Ya en el segundo es } \\
\text { más informal pues trata de una } \\
\text { persona que en aquel momento } \\
\text { estaba más desocupado e iría } \\
\text { escribir en aquel momento. (Marla) }\end{array}$ & $\begin{array}{l}\text { - La estructura del texto A es un } \\
\text { lenguaje más formal. La estructura } \\
\text { del texto B es un lenguaje más } \\
\text { coloquial. (Flávia) } \\
\text { - La estructura del texto A es... un } \\
\text { lenguaje más formal. En B, el } \\
\text { lenguaje es coloquial, que se ve en } \\
\text { los textos en la escuela. (Rosinha) } \\
\text { - El texto A tiene estructura de texto } \\
\text { más formal, usando vocabulario } \\
\text { correcto para el momento. El texto B } \\
\text { tiene su estructura más informal } \\
\text { utilizado para hablar con la gente } \\
\text { cercana. (Lima) } \\
\text { - La estructura del texto A: es formal. } \\
\text { La estructura del texto B: es } \\
\text { cologuial. (Belinha) }\end{array}$ & $\begin{array}{l}\text { - La escritura del texto"A"es formal } \\
\text { es más usada en oficinas. La } \\
\text { escritura del texto "B" es coloquial } \\
\text { usado en conversas de celular. } \\
\text { (María) } \\
\text { Los dos textos presentan } \\
\text { diferentes estructuras: Un formal y } \\
\text { la otra informal. En el texto } \\
\text { informal, el lenguaje es más usual } \\
\text { entre amigos y familia; el otro el } \\
\text { uso se da en ambientes de trabajo. } \\
\text { (Assis Pereira) }\end{array}$ \\
\hline
\end{tabular}

Cuadro 3: Respuestas de los/as participantes.

Fuente: Elaborado por la autora a partir de las respuestas de los/as participantes al cuestionario diagnóstico.

Para la superación de los equívocos identificados, en las respuestas, es que sugerimos IM para el trabajo con esas cartas en sala de clase. En la próxima, sección las presentamos.

\section{Sugerencia de IM}

Como sugerencia, proponemos la inserción de explicaciones en las dos cartas para un trabajo contrastivo en sala de clase. Esas explicaciones, en forma de IM, acompañadas de las explicaciones del profesorado pueden auxiliar los aprendientes en la comprensión de los contenidos que necesitan manejar para escribir distintas cartas personales.

Como sugerencia, primero los estudiantes pueden hacer una lectura inicial de la imagen. Después, el profesor puede empezar la discusión para percibir qué ellos comprendieron y a partir de eso presentar más ejemplos y explicaciones.

Seguimos presentando las mismas cartas, pero con la denominación de Carta A2 y Carta B2:

LínguaTec, Instituto Federal de Educação, Ciência e Tecnologia do Rio Grande do Sul, Bento Gonçalves v. 3, n. 1, p. 45-70, jun. 2019. 


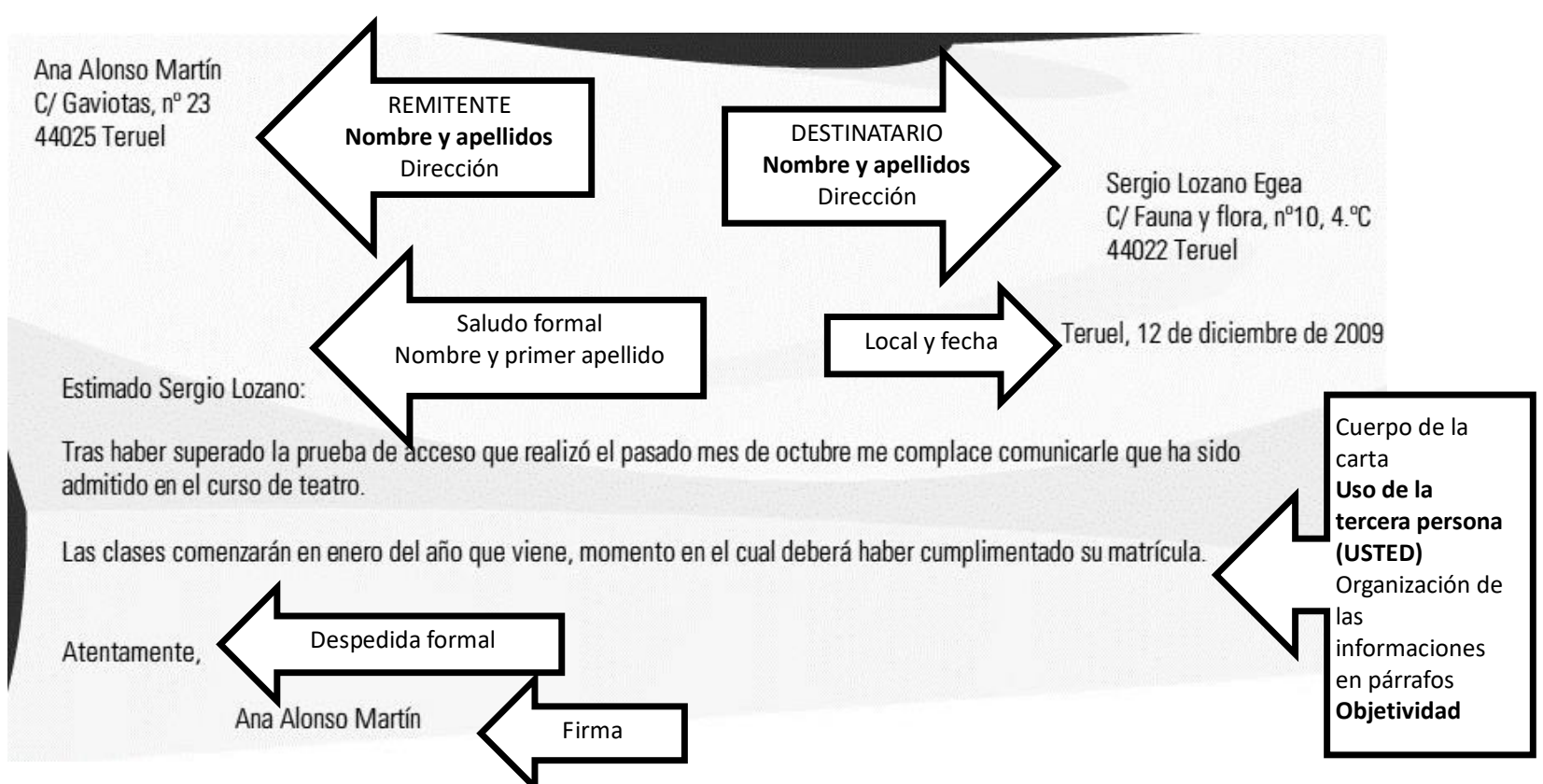

Figura 3: Carta A2

Fuente: Adaptado por la autora. Disponible en:

<https://www.edu.xunta.es/espazoAbalar/sites/espazoAbalar/files/datos/1285589414/contido/index.h tml>. Accedido en 05 de diciembre de 2016.

La indicación de las partes que componen la carta A2, en el texto, puede ser complementado con las siguientes informaciones, también empleando la IM, demostradas en el Cuadro 4:

\begin{tabular}{|l|l|}
\hline $\begin{array}{l}\text { Partes que componen la carta } \\
\text { personal profesional }\end{array}$ & $\begin{array}{l}\text { Cl tenor debe ser marcado en el texto, generalmente, de modo } \\
\text { formal, con nombre, apellidos y dirección en la parte superior } \\
\text { izquierda de la hoja. }\end{array}$ \\
\hline Remitente & $\begin{array}{l}\text { El tenor debe ser marcado en el texto, generalmente, de modo } \\
\text { formal, con nombre, apellidos y dirección en la parte superior } \\
\text { derecha de la hoia, una línea abaio de la del remitente. }\end{array}$ \\
\hline Saludo yecalinatario fecha & $\begin{array}{l}\text { Debe constar en la correspondencia a la derecha, ángulo superior, } \\
\text { una línea abajo. Primero el lugar, después la fecha separada por } \\
\text { rnma }\end{array}$ \\
\hline Cuerpo de la carta & $\begin{array}{l}\text { Debe constar una fórmula mediante la cual nos dirigimos al } \\
\text { destinatario. El tenor del escrito queda establecido a partir del } \\
\text { momento em aue usted se dirige al destinatario. }\end{array}$ \\
\hline Debe constar el contenido (campo) de que trata la carta. La escoja \\
todo debe ser coherente con el tono formal.
\end{tabular}

LínguaTec, Instituto Federal de Educação, Ciência e Tecnologia do Rio Grande do Sul, Bento Gonçalves v. 3, n. 1, p. 45-70, jun. 2019. 


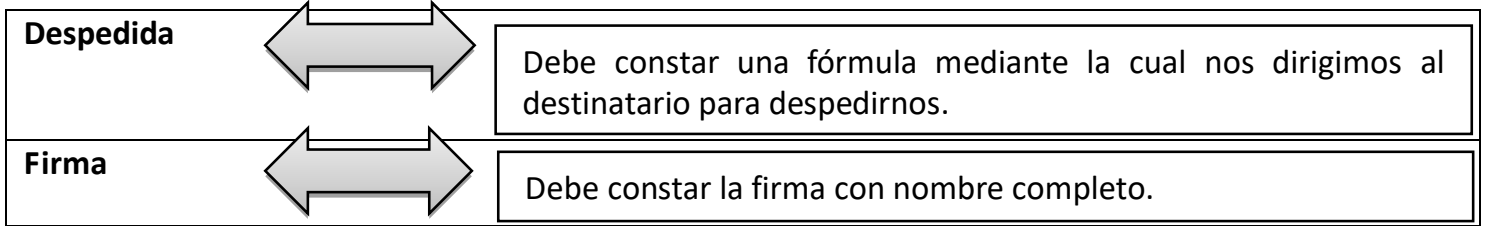

Cuadro 4: Informaciones complementares - Carta personal profesional

Fuente: Elaborado por la autora a partir de los ejemplos de cartas estudiadas y de Reyes (1999).

Presentamos, a seguir, una propuesta de IM para la carta B2.
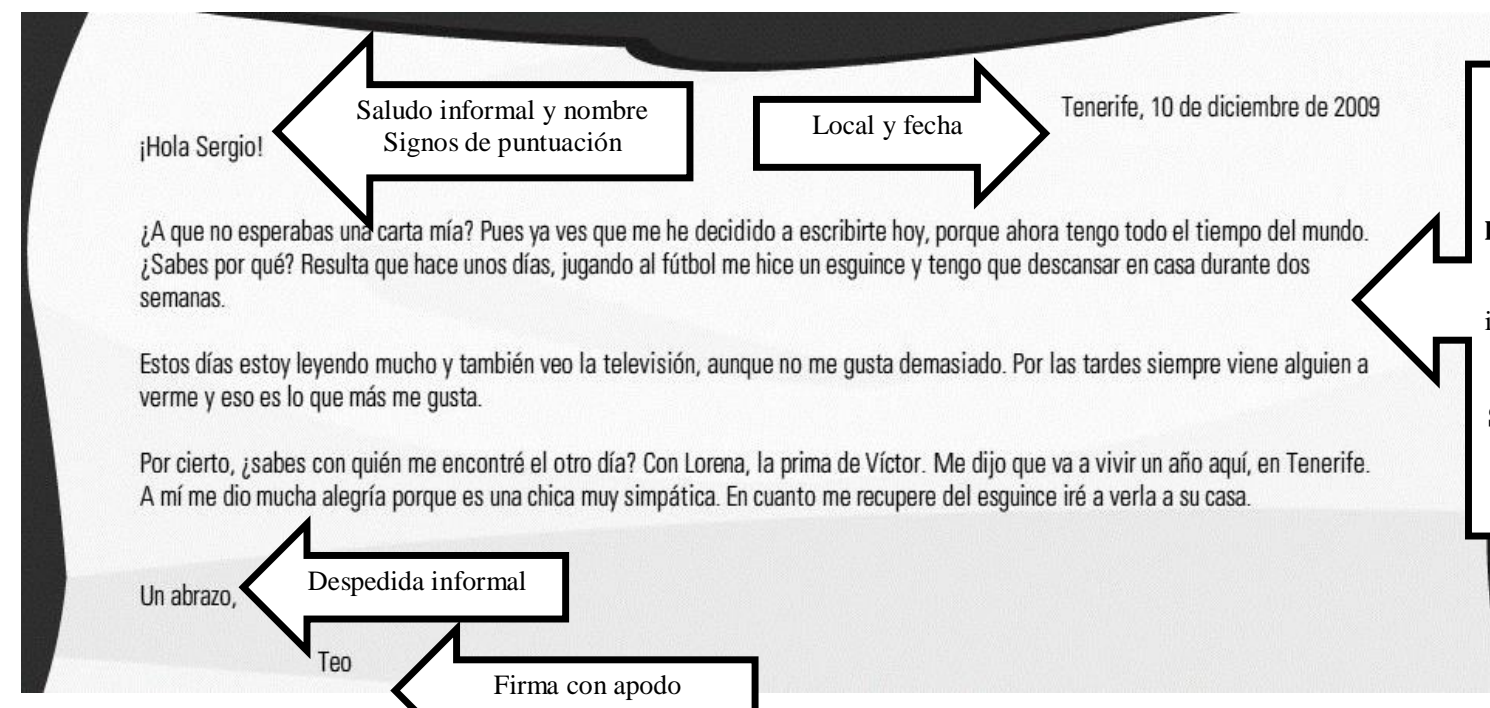

¿Sabes por qué? Resulta que hace unos días, jugando al fútbol me hice un esguince y tengo que descansar en casa durante dos semanas.

Estos días estoy leyendo mucho y también veo la televisión, aunque no me gusta demasiado. Por las tardes siempre viene alguien a verme y eso es lo que más me gusta.

Por cierto, ¿sabes con quién me encontré el otro día? Con Lorena, la prima de Víctor. Me dijo que va a vivir un año aquí, en Tenerife.

A mí me dio mucha alegría porque es una chica muy simpática. En cuanto me recupere del esguince iré a verla a su casa.

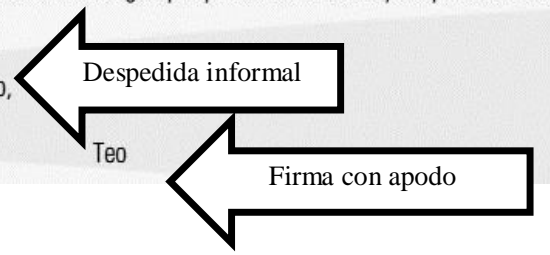

Figura 4: Carta B2

Fuente: Adaptado por la autora. Disponible en:

<https://www.edu.xunta.es/espazoAbalar/sites/espazoAbalar/files/datos/1285589414/contido/index.h $\underline{\mathrm{tml}}>$. Accedido en 05 de diciembre de 2016.

Las partes que componen la carta B2, señaladas en el texto, pueden ser complementadas con las siguientes informaciones con el uso, más una vez de una IM, como, por ejemplo:

\begin{tabular}{|l|l|}
\hline $\begin{array}{c}\text { Partes que componen la carta } \\
\text { personal privada }\end{array}$ & \multicolumn{1}{|c|}{ Características } \\
\hline Local y fecha Remitente & $\begin{array}{l}\text { Debe constar en la correspondencia personal privada a la } \\
\text { derecha, ángulo superior. Primer el lugar, después la fecha } \\
\text { separada por coma. }\end{array}$ \\
\hline Saludo & $\begin{array}{l}\text { Debe constar una fórmula mediante la cual nos dirigimos al } \\
\text { destinatario. El tenor del escrito queda establecido a partir } \\
\text { del momento en que usted se dirige al destinatario. }\end{array}$ \\
\hline
\end{tabular}

LínguaTec, Instituto Federal de Educação, Ciência e Tecnologia do Rio Grande do Sul, Bento Gonçalves v. 3, n. 1, p. 45-70, jun. 2019. 


\begin{tabular}{|l|l|}
\hline Destinatario & $\begin{array}{l}\text { El tenor debe ser marcado en el texto, generalmente, de } \\
\text { modo informal, con nombre o apodo, abajo de la } \\
\text { dirección, en la parte superior derecha de la hoja, una } \\
\text { línea abajo de la fecha. Acompañado de un saludo. }\end{array}$ \\
\hline Cuerpo de la carta & $\begin{array}{l}\text { Debe constar el contenido (campo) de que trata la carta. } \\
\text { La escoja de las palabras, la orden de presentación de las } \\
\text { informaciones. Todo debe ser coherente con el tono } \\
\text { informal. }\end{array}$ \\
\hline Respedida & $\begin{array}{l}\text { Debe constar una fórmula mediante la cual nos dirigimos } \\
\text { al destinatario para despedirnos. Indica intimidad con el } \\
\text { destinatario. }\end{array}$ \\
\hline
\end{tabular}

Cuadro 5: Informaciones complementares - Carta personal privada

Fuente: Elaborado por la autora a partir de los ejemplos de cartas estudiadas y de Reyes (1999).

Resaltamos que los contenidos que constan en las sugerencias no son completos en si mismos. Mucho se debe investigar y añadir en relación a aspectos lingüísticos, discursivos y de uso.

Presentamos, a continuación, una sugerencia de una propuesta didáctica de actividades que propone a atender a las necesidades de los estudiantes participantes de la investigación. El desarrollo de las actividades y el resultado de la aplicación de esa sugerencia serán temas de otro informe de investigación. Las actividades fueron planteadas para clases de 0:50min y al final de las cuatro primeras, los estudiantes con la ayuda del profesor sistematizan los contenidos estudiados y elaboran los criterios para producción/corrección. Sigue la sugerencia:

\begin{tabular}{|l|l|}
\hline Clase & \multicolumn{1}{|c|}{ Actividades } \\
\hline 1 & $\begin{array}{l}\text {-Presentación del tema. Dinámica: Una correspondencia para usted. Lectura de diferentes } \\
\text { correspondencias. Cada alumno comenta sobre las características de la carta que recibió. } \\
\text { Discusión: ¿Cuándo y para qué se escriben correspondencias? } \\
\text { - Capitalización de los contenidos estudiados. } \\
\text { - Criterios de producción y corrección. }\end{array}$ \\
\hline 2 & $\begin{array}{l}\text {-Análisis de diferentes contextos en que se usa correspondencia. Enumeración de los tipos de } \\
\text { correspondencia del contexto de una oficina / empresa, usando IM. Actividades orales y } \\
\text { escritas. } \\
\text { - Capitalización de los contenidos estudiados. } \\
\text { - Criterios de producción y corrección. }\end{array}$ \\
\hline 3 & - Contraste entre carta personal formal e informal. Lectura de cartas. Actividades de análisis de \\
\hline
\end{tabular}

LínguaTec, Instituto Federal de Educação, Ciência e Tecnologia do Rio Grande do Sul, Bento Gonçalves v. 3, n. 1, p. 45-70, jun. 2019. 


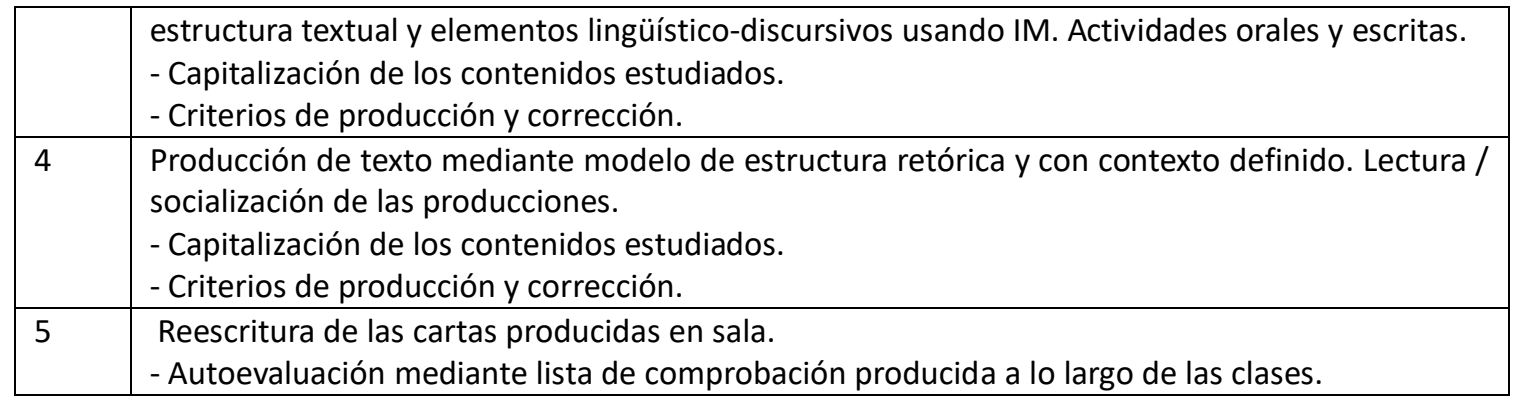

Cuadro 6: Sugerencia de una secuencia didáctica

Fuente: Elaborado por la autora.

La propuesta comprende actividades de lectura y escrita de modo integrado al análisis lingüístico-discursivo y retórico. La producción final deberá ser un texto más próximo a los textos estudiados y atendiendo al propósito comunicativo de la propuesta de producción de texto. La experiencia podrá ayudar a los alumnos en la construcción de otros tipos de correspondencia como mensaje de e-mail, carta de queja y carta de reclamación, por ejemplo.

\section{A modo de conclusión}

La propuesta didáctica con el uso de IM se presenta sencilla. La sencillez traduce, sin embargo, las múltiples posibilidades de uso didáctico en sala de clase. El camino para elaborarla constituyó un momento de reflexión y aprendizaje de usos de IM en sala de clase. Ella pudo también proporcionar y fomentar otros modos de presentación de contenidos para las clases de producción de texto referentes a la escrita de cartas. Además de posibilitar modos diferentes de organización de la clase, que dependen de la organización didáctica del profesor, de las necesidades de los discentes y de la finalidad del contexto de enseñanza y aprendizaje.

El uso de IM es un recurso que debe ser más explotado en las clases de producción de texto. Los aprendices pueden sacar mucho provecho de esquemas que les apoyen en la tarea de escribir textos de diferentes géneros. Eso porque ellos pueden identificar además de la estructura, los elementos que componen cada parte que estructura el texto. Aún, los estudiantes pueden construir otras posibilidades de uso de la IM estudiada. Y, más seguramente, cuando esos esquemas se relacionan a las necesidades específicas de los 
estudiantes, más ellos pueden potenciar el aprendizaje.

\section{Referencias}

BENESCH, S. Needs Analysis and curriculum development in EAP: An example of a critical approach. In: TESOL Quarterly, v. 30, 1996. p.723-738.

BENESCH, S. Rights analysis: studying power relations in an academic setting. English for Specific Purposes. In.: HYLAND, K. English for academic purposes: an advanced resource book. New York: Routledge, 2006, p.180-185.

BUSTO, N. B.; BEDOYA, M. G. La explotación de una imagen en la clase de E/LE. RedELE revista electrónica de didáctica / español lengua extranjera, 2009. Disponible en: <http://www.mecd.gob.es/dctm/redele/MaterialRedEle/Revista/2009_16/2009_redELE_16_0 1Barrallo.pdf?documentld=0901e72b80dd7388>. Accedido en: 30 de abr. de 2017.

CINTRA, A. M. M. Português Instrumental para Fins Acadêmicos: A análise de Necessidades. The ESPecialist, São Paulo, vol.13, no 2, 1992, p.117-132.

CINTRA, A. M. M; PASSARELLI, L. G. Revisitando o ensino de língua portuguesa para fins específicos. In.: CINTRA, A. M. M. (Org.). Ensino de língua portuguesa: reflexão e ação. São Paulo: EDUC, 2008, p.59-72.

DEAN, D. Genre theory: teaching, writing, and being. 2008.

DEVITT, A. J. Generalizing about Genre: New Conceptions of an Old Concept. College Composition and Communication, Vol. 4, №. 4, December,1993.

. Writing Genres. Southern Illinois University Press, 2004.

HYLAND, K. Genre and second language writing. United States of America: University of Michigan Press, 2004.

MILLER, C. R. Genre as social action. Quarterly Journal of Speech, National Communication association: 1984, p. 151-167.

Rhetorical Community: The Cultural Basis of Genre. In.: FREEDMAN, A.; MEDWAY, P. (orgs.), Genre and the New Rhetoric. Londres/Bristol, Taylor Francis, 1994, p. 67-78.

REYES, G. Cómo escribir bien en español: Manual de Redacción. 2 ed. Madrid: Arco Libros, 1999.

SIMÓN, F. R. La imagen metalingüística como imagen pedagógica en E/LE. RedELE revista 
electrónica de didáctica / español lengua extranjera, 2016. Disponible en: http://www.mecd.gob.es/dctm/redele/Material-

RedEle/Revista/201628/redele20165romofrancisco.pdf?documentld=0901e72b8204dfb3.

Accedido en: 30 de mar. de 2017.

SONGHORI, M. H. Introduction to needs analysis. In: English for Specific Purposes World, [s.l.], v.7, n. 4, 2008.

SWALES, J. M. Genre Analysis: English in academic and research settings. 12 ed. Cambridge: Cambridge University Press, 1990.

VICENTE, M. El manejo didáctico de la imagen. Cuaderno de Pedagogía Universitaria. Santiago, Rep. Dom.: PUCMM. Año 10/ N. 19 /enero-junio 2013, p. 7-13.Disponible en: http://www.pucmm.edu.do/STI/campus/CDP/ComuncacionPublicaciones/Paginas/Cuaderno dePedagogiaUniversitaria.aspx>. Accedido en: 30 de abr. de 2017.

Data de submissão: 03/04/2019. Data de aprovação: 16/05/2019. 